\title{
Sistem Pendukung Keputusan Menentukan Calon Sekretaris Terbaik Desa Sekarjalak Menggunakan Simple Additive Weighting
}

\author{
Faiza Rizqi Irawan ${ }^{1}$, Mukhamad Nurkamid. ${ }^{2}$ \\ ${ }^{1}$ Fakultas Teknik Informatika-Universitas Muria Kudus \\ ${ }^{2}$ Fakultas Teknik Informatika-Universitas Muria Kudus \\ Emaill: ${ }^{1} 201851234 @$ std.umk.ac.id, ${ }^{2}$ muhammad.nurkamid@umk.ac.id
}

(Naskah masuk: 11 April 2021, diterima untuk diterbitkan: 7 Mei 2021)

\begin{abstract}
Abstrak
Dalam memilih sekretaris desa di Desa Sekarjalak dilakukan oleh kepala desa langsung. Menentukan sekretaris di Desa Sekarjalak dinilai tidak efektif, karena dalam menentukan mana yang pantas dan tidaknya menjadi sekretaris di Desa Sekarjalak. Aplikasi sistem pendukung keputusan menentukan calon sekretaris terbaik di Desa Sekarjalak menggunakan Simple Additive Weighting. Langkah pertama yaitu memberikan bobot untuk setiap kriteria, langkah selanjutnya yaitu perangkingan untuk menentukan alternatif tertinggi dari seluruh alternatif yang tersedia. Alternatif tertinggi ini merupakan hasil yang pantas diterima sebagai sekretaris baru yang sudah teruji yang didasarkan pada kriteria-kriteria yang sudah ditentukan. Penelitian ini menghasilkan, sistem yang dibangun dapat memudahkan Kepala Desa dalam menentukan sekretaris desa yang memenuhi standrart, sehingga dapat melaksanakan tugas dan tanggung jawab yang diberikan ke sekretaris desa.
\end{abstract}

Kata kunci : sistem pendukung keputusan, SAW, Web.

\section{Decision Support System Determine the Best Candidate for Secretary of Sekarjalak Village Using Simple Additive Weighting}

\begin{abstract}
In selecting the village secretary in Sekarjalak Village, the village head directly chooses. Determining the secretary in Sekarjalak Village is considered ineffective, because in determining which one is appropriate or not to be a secretary in Sekarjalak Village. The decision support system application determines the best candidate for secretary in Sekarjalak Village using Simple Additive Weighting. The first step is to give weight to each criterion, the next step is ranking to determine the highest alternative from all available alternatives. This highest alternative is a result that deserves to be accepted as a new secretary who has been tested based on predetermined criteria. This research resulted in the system being built to make it easier for the Village Head to determine the village secretary who meets the standards, so that he can carry out the duties and responsibilities assigned to the village secretary.
\end{abstract}

Keywords : decision support system, SAW, Web.

\section{PENDAHULUAN}

Sekretaris desa atau biasa disebut Perangkat Desa merupakan unsur staf yang membantu Kepala Desa dalam membuat dan mengkoordinasi yang diwadahi dalam sekretaris desa, dan membantu tugas Kepala Desa dalam melaksanakan kebijakan dalam bentuk pelaksana teknis dan unsur kewilayahan. (Haryanto, 2018)

Pemilihan sekretaris desa di Desa Sekarjalak dipilih oleh kepala desa itu sendiri, tidak dilakukan secara demokrasi. Pemilihan sekretaris di Desa Sekarjalak tidak efektif, karena kurangnya perhatian dalam menyeleksi mana yang layak dan tidaknya menjadi sekretaris desa tersebut.
Sistem Pendukung Keputusan merupakan sistem informasi interaktif yang menyediakan informasi pemodelan, dan pemanipulasian data. Sistem ini biasa digunakan dalam mengambil sebuah keputusan dalam situasi yang terstruktur maupun semistruktur, dimana seseorang tidak tahu bagaimana keputusan itu harus dibuat. (Kusrini, 2007)

Berdasarkan masalah di atas dibutuhkan suatu sistem yang dapat mempermudah Kepala Desa dalam memilih sekretaris desa yang sudah memenuhi persyaratan sehingga mampu mengerjakan tugas dan tanggung jawab yang diberikan kepada sekretaris desa. 
Berikut ini beberapa penelitian sebelumnya tentang Pemilihan Rumah Tinggal di Perumahan(saw) (Adianto, 2017), Penerimaan Beasiswa dengan Metode SAW (Sri, 2011), Pemilihan Karyawan Terbaik pada PT Kujang Sakti Anugrah (Simple Additive Weighting) (Penta, 2019), Penerimaan Karyawan Di Gbi Kudus (Parabang Daud, 2019), Impelemtasi SPK Dalam Pemilihan Dosen Berprestasi (Rahagukguk, 2017). Diharapkan dengan penggunaan sistem ini dapat memudahkan kepala desa menentukan keputusan calon sekretaris desa.

\section{METODE PENELITIAN}

Metode penelitian dapat disebut sebagai kerangka pikir yang dapat dijadikan sebagai pedoman penelitian. Metode penelitian merupakan rencana kerja yang sistematis.

\subsection{Kerangka Penelitian}

a. Jenis dan Sumber Data

Jenis Data

- Data Kuantitatif

Data kuantitatif yaitu jenis data dalam bentuk dokumen yang dapat dihitung dan menunjukkan jumlahnya. Data kuantitatif dalam penelitian ini yaitu data calon sekretaris desa (CV).

- Data Kualitiatif

Data Kualitatif yaitu jenis data yang tidak berbentuk dokumen dan tidak dapat dihitung jumlahnya. Data kualitatif dalam penelitian ini yaitu tentang prosedur penentuan sekretaris desa.

Sumber Data

- Data Primer, yaitu data yang diperoleh dengan cara studi langsung ke Kantor Kepala desa Sekarjalak dengan cara wawancara dan observasi dengan Kepala Desa Sekarjalak.

- Data Sekunder, yaitu data yang diperoleh secara tidak langsung dengan tujuan menambah pengetahuan dan ringkasan, antaralain data yang diambil dari studi pustaka atau data pendukung lainya yang bukan dari sumber utama yang berhubungan dengan penelitian ini.

b. Identifikasi Masalah

Tahap ini perlu dilakukan agar peneliti benar-benar dapat menemukan permasalahan yang terjadi, tahap ini dibangun berdasarkan rumusan masalah pada latar belakang masalah. Hasil identifikasi masalah pada penelitian ini adalah dalam menentukan sekretaris desa yang selama ini dilakukan secara manual dan membutuhkan waktu yang lama dalam mengambil keputusan dan bisa saja terjadi subjektifitas dalam pengambilan keputusan menjadi salah satu permasalahan yang ada di desa Sekarjalak, berdasarkan informasi dari Kepala desa. Oleh karena itu dalam mengambil keputusan untuk menentukan sekretaris desa diperlukan sebuah sistem pendukung keputusan agar tidak terjadi subjektifitas dalam pengambilan keputusan.

c. Pengumpulan Data

Tahap pengumpulan data dibutuhkan dalam melakukan sebuah penelitian, adapun pengumpulan data tersebut sebagai berikut :

1. Wawancara

Wawancara seagai media komunikasi dua arah untuk memperoleh data atau informasi dari narasumber (Kepala Desa Sekarjalak) dengan mengajukan beberapa pertanyaan (Jogiyanto Hartono, 2005). Wawancara dilakukan demi mendapatkan jawaban dari pertanyaan yang terkait dengan permasalahan yang dihadapi dan permasalahan saat proses penentuan calon sekretaris desa yang sedang berjalan.

2. Observasi

Observasi untuk mendapatkan data atau informasi dengan melakukan mengamati, mencatat apa saja yang penting dalam menentukan sekretaris desa untuk mendapatkan informasi yang dibutuhkan.

3. Studi Pustaka

Teknik pengumpulan data dengan membaca, meninjau dan mengutip buku, artikel, jurnal penelitian sebelumnya.

d. Tahap Analisa Kebutuhan

Tahap Analisa kebutuhan mencakup proses untuk mendapatkan informasi, model dan spesifikasi tentang perangkat lunak yang akan dibuat.

e. Tahap Implementasi

Mengimplementasikan program serta melakukan pengecekan semua bagian sistem.

f. Tahap Pengujian

Menguji sistem terhadap semua fitur untuk memastikan sistem berjalan dengan baik. 


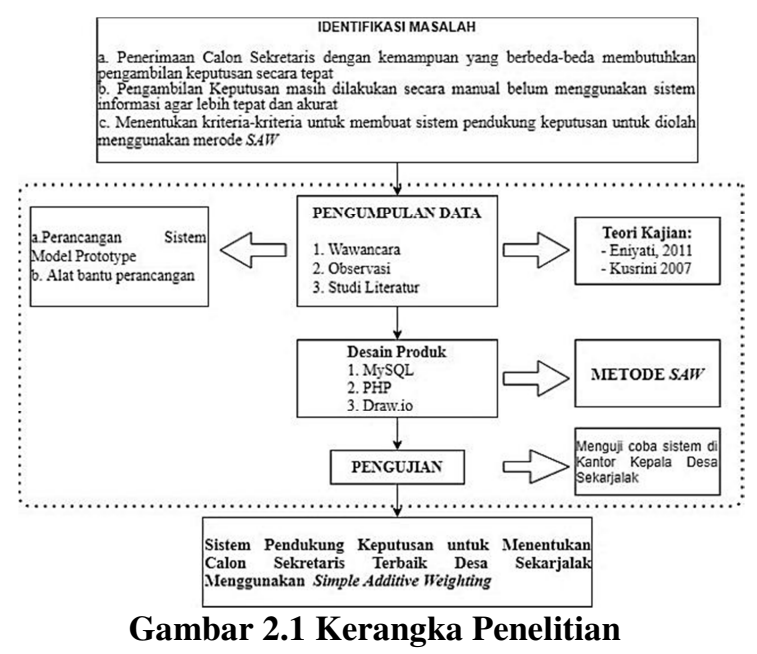

\subsection{Metode Simple Additive Weighting (SAW)}

Metode $S A W$ dengan normalisasi matriks keputusan (X) kesuatu skala yang dapat diperbandingkan dengan semua rating alternatif yang ada. (Munthe, 2013)

Adapun langkah penyelesaian suatu masalah menggunakan metode Simple Additive Weighting yaitu :

1. Peneliti menetapkan kriteria yang nantinya dijadikan pedoman $(\mathrm{Cj})$.

2. Memberi nilai bobot untuk setiap kriteria (W).

3. Memberi nilai alternatif pada setiap kriteria.

4. Menghasilkan matriks keputusan berdasarkan kriteria (Cj), kemudian dilakukan normalisasi matriks berdasarkan persamaan yang disesuaikan dengan atributnya (atribut keuntungan ataupun atribut biaya) sehingga diperoleh matriks ternormalisasi $\mathrm{R}$.

$R_{i j}=\frac{X_{i j}}{\operatorname{Max} X_{i j}} \mathrm{Jika} \mathrm{j}$ adalah atribut keuntungan (benefit)

$$
R_{i j}=\frac{X_{i j}}{\operatorname{Min} X_{i j}} \text { Jika } \mathrm{j} \text { adalah atribut biaya (cost) }
$$

Keterangan :

$$
\begin{array}{cc}
R_{i j} \quad= & \text { Normalisasi } \\
X_{i j} \quad= & \text { Nilai atribut yang dimiliki } \\
& \text { oleh setiap kriteria } \\
\text { Max } X_{i j}= & \text { Nilai terbesar dari setiap } \\
& \text { kriteria } \\
\text { Max } X_{i j}= & \text { Nilai terkecil dari setiap } \\
& \text { kriteria }
\end{array}
$$

5. Hasil akhir diperoleh dari proses perangkingan yaitu penjumlahan dan perkalian matriks ternormalisasi $\mathrm{R}$, dengan vektor bobot sehingga diperoleh nilai tertinggi yang dipilih sebagai alternatif yang baik sebagai solusi.

$$
V_{i}=\sum_{j=1}^{n} W_{j} R_{i j}
$$

Keterangan :

$$
\begin{aligned}
V_{i} & =\text { Nilai akhir dari alternatif } \\
W_{j} & =\text { Bobot yang telah ditentukan } \\
R_{i j} & =\text { Normalisasi }
\end{aligned}
$$

\section{PEMBAHASAN}

\subsection{Analisa Masalah}

Hasil dari pengumpulan data yaitu adanya masalah dalam menentukan sekretaris di Desa Sekarjalak yaitu belum adanya sistem pendukung keputusan menentukan sekretaris desa.

Dalam pengambilan keputusan, kita dihadapkan dengan berbagai pilihan diantaranya mengambil suatu keputusan. Dalam suatu hal pemilihan calon sekretaris Desa Sekarjalak, sebaiknya memikirkan bagaimana keputusan yang diambil, dapat menjadi suatu keputusan yang baik, tepat dan akurat. Pemilihan sekretaris di Desa tidak efektif, karena dalam menentukan mana yang pantas dan tidaknya menjadi sekretaris di Desa Sekarjalak. Maka sangat mungkin kepala desa mengambil keputusan memilih sekretaris yang tidak memenuhi standart.

\subsection{Analisa kebutuhan}

Dalam membangun sistem pendukung keputusan untuk menentukan calon sekretaris terbaik desa sekarjalak Menggunakan Simple Additive Weighting, data yang dibutuhkan sebagai berikut :

1. Kriteria

2. Bobot kriteria

3. Nilai kriteria

\subsection{Pemodelan Simple Additive Weighting}

Proses menentukan calon sekretaris terbaik desa sekarjalak dimulai dari melihat pendidikan terkahir, pengalaman kerja, perilaku, usia, status kependudukan, kemampuan, prestasi, dan kelengkapan administrasi (Haryanto, 2018).

\begin{tabular}{lccc}
\multicolumn{1}{c}{ Kriteria } & Variabel & Bobot & Atribut \\
\hline Pengalaman Kerja & C1 & 20 & Benefit \\
Perilaku & C2 & 15 & Benefit \\
Usia & C3 & 5 & Benefit \\
Status Kependudukan & C4 & 5 & Benefit \\
Kemampuan & C5 & 35 & Benefit \\
Prestasi & C6 & 20 & Benefit \\
\hline
\end{tabular}

\section{Tabel 1 Tabel Kriteria dan Bobot}

\begin{tabular}{ccc}
\hline No & Pengalaman Kerja & Skor \\
\hline 1 & Tidak pernah bekerja & 50 \\
2 & $1-2$ Tahun & 60 \\
3 & $3-4$ Tahun & 70
\end{tabular}




\begin{tabular}{ccc}
4 & $5-6$ Tahun & 80 \\
5 & $>7$ Tahun & 90 \\
\hline \multicolumn{3}{|c}{ Tabel 2 Skor Pengalaman Kerja } \\
\hline \multicolumn{3}{r}{} \\
\hline No & Perilaku & Skor \\
\hline 1 & Cukup & 60 \\
2 & Baik & 70 \\
3 & Sangat Baik & 80 \\
\hline
\end{tabular}

Tabel 3 Skor Perilaku

\begin{tabular}{ccc}
\hline No & Usia & Skor \\
\hline 1 & $17-20$ Tahun & 70 \\
2 & $21-25$ Tahun & 85 \\
3 & $26-30$ Tahun & 80 \\
\hline \multicolumn{3}{c}{ Tabel 4 Skor Usia } \\
\hline \multicolumn{3}{c}{} \\
\hline No & Status Kependudukan & Skor \\
\hline 1 & Tidak Tetap & 60 \\
2 & Tetap & 70 \\
\hline
\end{tabular}

Tabel 5 Skor Status Kependudukan

\begin{tabular}{clc}
\hline No & \multicolumn{1}{c}{ Kemampuan } & Skor \\
\hline 1 & $\begin{array}{l}\text { Ms. Word } \\
\text { Ms. Word, Ms. Excel, }\end{array}$ & 60 \\
2 & $\begin{array}{l}\text { Ms. Access, Powerpoint } \\
\text { Ms. Word, Ms. Excel, }\end{array}$ & 80 \\
3 & $\begin{array}{l}\text { Powerpoint, PHP } \\
\text { Ms. Word, Ms. Excel, }\end{array}$ & 90 \\
4 & Powerpoint, PHP, C++
\end{tabular}

Tabel 6 Skor Kemampuan

\begin{tabular}{ccc}
\hline No & Prestasi & Skor \\
\hline 1 & Tidak Ada & 60 \\
2 & Ada & 80 \\
\hline
\end{tabular}

Tabel 7 Skor Prestasi

Data berikut ini ditentukan untuk penggunaan persamaan dan menentukan bobot dari tiap kriteria untuk proses menentukan calon sekretaris terbaik desa sekarjalak ditunjukkan pada Tabel 2.

\begin{tabular}{|c|c|c|c|c|c|c|c|c|}
\hline Nama & Pendidikan & \begin{tabular}{|l} 
Pengalaman \\
Kerja(Thn) \\
\end{tabular} & Perilaku & Usia (Thn) & $\begin{array}{c}\text { Status } \\
\text { kependuduka }\end{array}$ & Kemampuan & Prestasi & Administrasi \\
\hline $\begin{array}{l}\text { Faiza Rizqi } \\
\text { lrawan } \\
\end{array}$ & $\$ 1$ & 1 & Baik & 21 & Tetap & $\begin{array}{l}\text { Ms Excel, Ms } \\
\text { Word, PHP, C+ }\end{array}$ & Tidak Ada & $\begin{array}{c}\text { Lengksp (Surat } \\
\text { Keterangan, Fotococy } \\
\text { ljazah,Psss Foto, DII) }\end{array}$ \\
\hline $\begin{array}{l}\text { Latifun Nisa } \\
\text { Irawan }\end{array}$ & SMA & $\begin{array}{l}\text { Tidak Pernah } \\
\text { Bekerja }\end{array}$ & Baik & 19 & Tetap & $\begin{array}{l}\text { Ms Excel, Ms } \\
\text { Word, PHP, } \\
\text { Powerpoint }\end{array}$ & TidakAda & $\begin{array}{l}\text { Kurang Lengkap (Tidak } \\
\text { Ada Surat Keterangan) } \\
\text { Kurang Leng kap (Tidak }\end{array}$ \\
\hline Suho & 03 & 2 & $\begin{array}{l}\text { Sangat } \\
\text { Baik }\end{array}$ & 30 & Tetap & $\begin{array}{l}\text { Ms Excel, Ms } \\
\text { Word, PHP, } \\
\text { Powerpoint }\end{array}$ & \begin{tabular}{|l|} 
Micrososoft \\
Office \\
Specialist \\
ACTTON \\
A
\end{tabular} & $\begin{array}{c}\text { Lengkap (Surat } \\
\text { Keterangan, Fotocopy } \\
\text { ljazzh, Pass Foto, Dll) } \\
\end{array}$ \\
\hline Aldebaran & $\$ 1$ & 5 & Cukup & 27 & TidakTetap & $\begin{array}{c}\text { Mss Excel, Ms } \\
\text { Word, Ms Access, } \\
\text { Ms Powerpoint }\end{array}$ & Tidak Ada & \begin{tabular}{|c} 
Tidak Lengkap (Tidak \\
Adal jazah, Pass Foto, \\
Surat Keterangann)
\end{tabular} \\
\hline
\end{tabular}

Tabel 8 Data Calon Sekretaris Desa

Tabel data calon sekretaris diinputkan susuai data, maka diperoleh data matriks $\mathrm{X}$ seperti yang ditunjukkan pada tabel 9 .

\begin{tabular}{lllllll}
\hline \multirow{2}{*}{ Alternatif Kriteria } \\
\cline { 2 - 7 } & C1 & C2 & C3 & C4 & C5 & C6 \\
\hline A1 & 60 & 70 & 75 & 80 & 90 & 60 \\
A2 & 50 & 70 & 70 & 80 & 80 & 60 \\
A3 & 60 & 80 & 80 & 80 & 80 & 80 \\
A4 & 80 & 60 & 80 & 60 & 60 & 60 \\
\hline
\end{tabular}

Tabel 9 X

$$
X=\left[\begin{array}{llllll}
60 & 70 & 85 & 80 & 90 & 60 \\
50 & 70 & 70 & 80 & 80 & 60 \\
60 & 80 & 80 & 80 & 80 & 80 \\
80 & 60 & 80 & 60 & 60 & 60
\end{array}\right]
$$

a. Kriteria Pengalaman Kerja, merupakan atribut keuntungan (benefit).

$$
\begin{aligned}
& R_{1.1}=\frac{60}{\operatorname{Max}\{60 ; 50 ; 60 ; 80\}}=\frac{60}{80}=0.75 \\
& R_{2.1}=\frac{50}{\operatorname{Max}\{60 ; 50 ; 60 ; 80\}}=\frac{50}{80}=0.625 \\
& R_{3.1}=\frac{60}{\operatorname{Max}\{60 ; 50 ; 60 ; 80\}}=\frac{60}{80}=0.75 \\
& R_{4.1}=\frac{80}{\operatorname{Max}\{60 ; 50 ; 60 ; 80\}}=\frac{80}{80}=1
\end{aligned}
$$

b. Kriteria Perilaku termasuk atribut keuntungan (benefit).

$$
\begin{aligned}
& R_{1.2}=\frac{70}{\operatorname{Max}\{70 ; 70 ; 80 ; 60\}}=\frac{70}{80}=0.875 \\
& R_{2.2}=\frac{70}{\operatorname{Max}\{70 ; 70 ; 80 ; 60\}}=\frac{70}{80}=0.875 \\
& R_{3.2}=\frac{80}{\operatorname{Max}\{70 ; 70 ; 80 ; 60\}}=\frac{80}{80}=1 \\
& R_{4.2}=\frac{60}{\operatorname{Max}\{70 ; 70 ; 80 ; 60\}}=\frac{60}{80}=0.75
\end{aligned}
$$

c. Kriteria Usia merupakan atribut keuntungan (benefit).

$$
\begin{aligned}
& R_{1.3}=\frac{85}{\operatorname{Max}\{85 ; 70 ; 80 ; 80\}}=\frac{85}{85}=1 \\
& R_{2.3}=\frac{70}{\operatorname{Max}\{85 ; 70 ; 80 ; 80\}}=\frac{70}{85}=0.823 \\
& R_{3.3}=\frac{80}{\operatorname{Max}\{85 ; 70 ; 80 ; 80\}}=\frac{80}{85}=0.94 \\
& R_{4.3}=\frac{80}{\operatorname{Max}\{85 ; 70 ; 80 ; 80\}}=\frac{80}{85}=0.94
\end{aligned}
$$

d. Kriteria Status Kependudukan termasuk atribut keuntungan (benefit).

$$
\begin{aligned}
& R_{1.4}=\frac{80}{\operatorname{Max}\{80 ; 80 ; 80 ; 60\}}=\frac{80}{80}=1 \\
& R_{2.4}=\frac{80}{\operatorname{Max}\{80 ; 80 ; 80 ; 60\}}=\frac{80}{80}=1 \\
& R_{3.4}=\frac{80}{\operatorname{Max}\{80 ; 80 ; 80 ; 60\}}=\frac{80}{80}=1 \\
& R_{4.4}=\frac{60}{\operatorname{Max}\{80 ; 80 ; 80 ; 60\}}=\frac{60}{80}=0.75
\end{aligned}
$$

e. Kriteria Kemampuan termasuk atribut keuntungan (benefit).

$$
\begin{aligned}
& R_{1.5}=\frac{90}{\operatorname{Max}\{90 ; 80 ; 80 ; 60\}}=\frac{90}{90}=1 \\
& R_{2.5}=\frac{80}{\operatorname{Max}\{90 ; 80 ; 80 ; 60\}}=\frac{80}{90}=0.89 \\
& R_{3.5}=\frac{80}{\operatorname{Max}\{90 ; 80 ; 80 ; 60\}}=\frac{80}{90}=0.89 \\
& R_{4.5}=\frac{60}{\operatorname{Max}\{90 ; 80 ; 80 ; 60\}}=\frac{60}{90}=0.67
\end{aligned}
$$

f. Kriteria Prestasi termasuk atribut keuntungan (benefit).

$$
R_{1.6}=\frac{60}{\operatorname{Max}\{60 ; 60 ; 80 ; 60\}}=\frac{60}{80}=0,75
$$




$$
\begin{aligned}
& R_{2.6}=\frac{60}{\operatorname{Max}\{60 ; 60 ; 80 ; 60\}}=\frac{60}{80}=0,75 \\
& R_{3.6}=\frac{80}{\operatorname{Max}\{60 ; 60 ; 80 ; 60\}}=\frac{80}{80}=1 \\
& R_{4.6}=\frac{60}{\operatorname{Max}\{60 ; 60 ; 80 ; 60\}}=\frac{60}{80}=0,75
\end{aligned}
$$

Dari persamaan matriks $\mathrm{X}$ diperoleh matriks $\mathrm{R}$ diperoleh dari persamaan normalisasi.

$\left[\begin{array}{cccccc}0.75 & 0.875 & 1 & 1 & 1 & 0.75 \\ 0.625 & 0.875 & 0.823 & 1 & 0.89 & 0.75 \\ 0.75 & 1 & 0.94 & 1 & 0.89 & 1 \\ 1 & 0.75 & 0.94 & 0.75 & 0.67 & 0.75\end{array}\right]$

Dari hasil perhitungan memperoleh nilai setiap alternatif dan nilai yang tertinggi terpilih sebagai calon sekretaris desa. Hasil nilai diurutkan dari yang tertinggi ke yang terrendah untuk memudahkan penentuan.

$V_{1}=(0.75 * 20)+(0.875 * 15)+(1 * 5)+(1 * 5)+$ $(1 * 35)+(0.75 * 20)=15+13.125+5+5+35+15$ $=88.125$

$V_{2}=(0.625 * 20)+(0.875 * 15)+(0.823 * 5)+(1 * 5)$

$+(0.89 * 35)+(0.75 * 20)=12.5+13.125+4.115+5$

$+31.15+15=80.89$

$V_{3}=(0.75 * 20)+(1 * 15)+(0.94 * 5)+(1 * 5)+$ $(0.89 * 35)+(1 * 20)=15+15+4.7+5+31.15+20$ $=90.85$

$V_{4}=(1 * 20)+(0.75 * 15)+(0.94 * 5)+(0.75 * 5)+$ $(0.67 * 35)+(0.75 * 20)=20+11.25+4.7+3.75+$ $23.45+15=78.15$

\begin{tabular}{clc}
\hline No & Nama Calon Sekretaris & Hasil \\
\hline 1 & Suho & 90,85 \\
2 & Faiza Rizqi Irawan & 88,125 \\
3 & Latifun Nisa Irawan & 80,89 \\
4 & Aldebaran & 78,15 \\
\hline
\end{tabular}

Tabel 10 Hasil Perhitungan

Dari hasil perhitungan maka Suho memperoleh nilai tertinggi, sementara Aldebaran memperoleh nilai terendah. Hasil tersebut dapat dijadikan bahan pertimbangan bagi kepala desa dalam menentukan calon sekretaris desa Sekarjalak.

\subsection{Perancangan Entity Relation Data (ERD)} untuk database 201851234.

Di bawah ini merupakan rancangan struktur relational database sistem pendukung keputusan untuk menentukan calon sekretaris terbaik desa sekarjalak menggunakan saw.

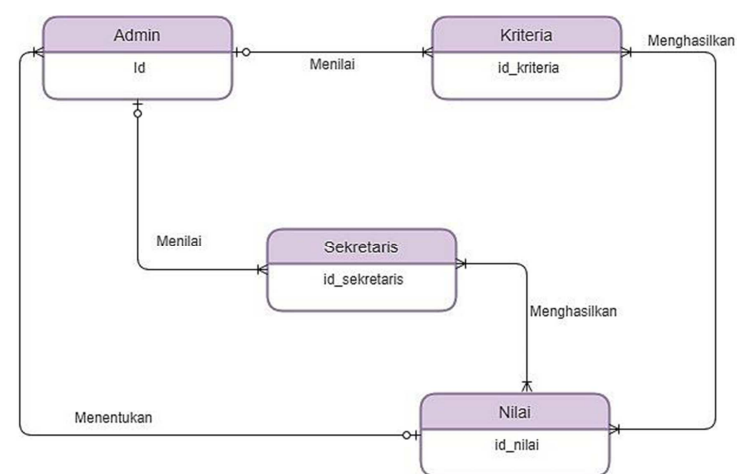

Gambar 3.3 Rancangan Struktur ERD

\subsection{DFD (Data Flow Diagram)}

DFD sistem pendukung keputusan untuk menentukan calon sekretaris terbaik desa sekarjalak menggunakan metode Simple Additive Weighting.

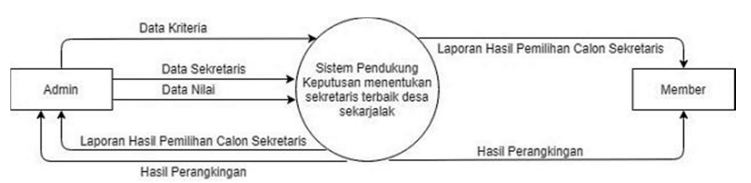

Gambar 3.4 DFD Lv 0

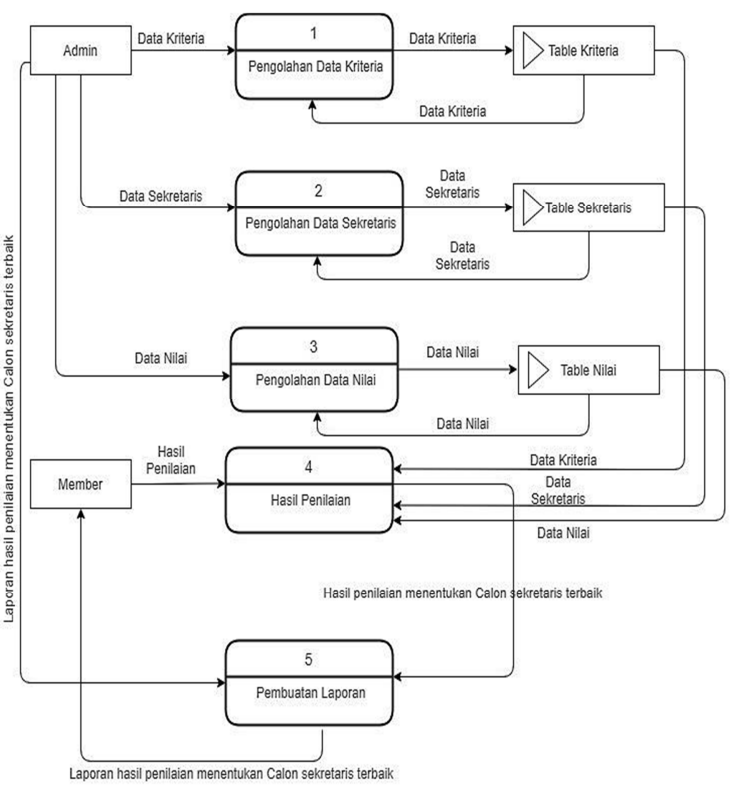

Gambar 3. 4 DFD Level 1

\section{Hasil}

Penelitian ini menghasilkan sebuah sistem pendukung keputusan menentukan calon sekretaris terbaik Desa Sekarjalak menggunakan Simple Additive Weighting. Tampilan dari sistem pada penelitian ini sebagai berikut :

a. Tampilan Perhitungan $S A W$

Halaman perhitungan SAW dibuat untuk mempermudah admin dalam melihat perhitungan yang didasarkan pada bobot yang sudah diinputkan 
untuk setiap kriteria dan menampilkan rangking berdasarkan hasil perhitungan tersebut.

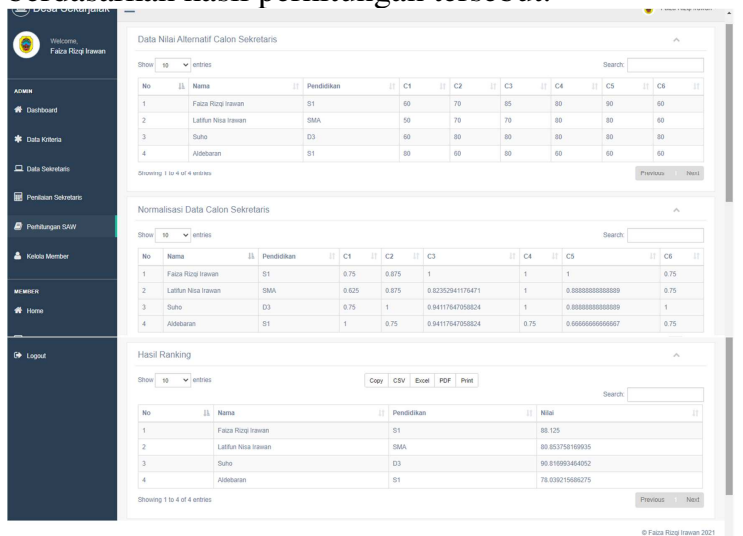

Gambar 4.a Tampilan Perhitungan $S A W$

\section{KESIMPULAN DAN SARAN}

sistem pendukung keputusan untuk menentukan calon sekretaris terbaik desa sekarjalak menggunakan simple additive weighting dapat ditarik kesimpulan antara lain :

1. Sistem ini dapat mempermudah mengambil sebuah keputusan menentukan calon sekretaris terbaik berdasarkan prioritas terhadap calon sekretaris. Informasi yang dihasilkan sistem ini menampilkan data total perhitungan dari setiap calon sekretaris.

2. Sistem ini membantu Kepala desa dalam menentukan calon sekretaris terbaik yang pantas dan sesuai standart kepala desa lebih cepat dibandingkan dengan menentukan secara spontan maupun manual.

Saran mengenai sistem pendukung keputusan untuk menentukan calon sekretaris terbaik desa sekarjalak menggunakan Simple Additive Weighting yang terlah dibuat :

1. Melakukan update aplikasi seperti menambahkan atau mengurangi fitur yang tersedia sesuai dengan kebutuhan.

2. Perlunya pemeliharaan agar program dapat digunakan dengan maksimal.

3. Melakukan evaluasi sistem secara keseluruhan agar dapat dilakukan penyesuaian sistem.

\section{DAFTAR PUSTAKA}

Adianto, T. A. (2017). Sistem pendukung keputusan pemilihan rumah tinggal di perumahan menggunakan metode simple additive weighting (saw)(studi kasus: Kota samarinda). Samarinda: Prosding 2nd SAKTI.
Haryanto. (2018). Peraturan Daerah Kabupaten Pati Nomor 11 Tentang Perangkat Desa. Pati: Bupati Pati.

Jogiyanto Hartono, M. (2005). Analisa dan Desain Sistem Informasi. Yogyakarta: Andi Offset.

Kusrini. (2007). Konsep dan Aplikasi Sistem Pendukung Keputusan. Yogyakarta: Andi Offset.

Munthe, H. G. (2013). Sistem Pendukung Keputusan Penentuan Prioritas Usulan Sertifikasi Guru Dengan Metode Simple Additive Weighting. Medan: ISSN: 2301-9425. Pelita Informatika Budi Darma Vol IV, No. 2 Agustus 2013: 52-58.

Parabang Daud, a. A. (2019). Pemodelan Saw Dalam Penentuan Penerimaan Karyawan Di Gbi Kudus. Indonesian Journal of Technology, Informatics and Science (IJTIS) $1.1: 1-4$.

Penta, M. F. (2019). Sistem Pendukung Keputusan Pemilihan Karyawan Terbaik Menggunakan Metode SAW pada PT. Kujang Sakti Anugrah. JSAI (Journal Scientific and Applied Informatics) 2:3.

Rahagukguk, D. M. (2017). Implementasi Metode Simple Additive Weighting (SAW) Pada Sistem Pendukung Keputusan Pemilihan Dosen Berprestasi. MEANS (Media Informasi Analisa dan Sistem) 2, no. 2 : 124-133.

Sri, E. (2011). Perancangan Sistem Pendukung Keputusan untuk Penerimaan Beasiswa dengan Metode SAW (Simple Additive Weighting). Jurnal Teknologi In Halamanasi DINAMIK. No.2, Volume 16 171-176.

Wanto, A. D. (2015). Analisis Penerapan Sistem Pendukung Keputusan Terhadap Seleksi Penerima Beasiswa BBM (Bantuan Belajar Mahasiswa) Pada Perguaruan Tinggi Menggunakan Metode Simple Additive Weighting (SAW). In Prosding Seminar Nasional Rekayasa (SNTR) II (Vol. 2, No.25, pp 323-333). 